\title{
Study on the Negative Transfer of Mother Tongue in College Students’ English Argumentative Writing
}

\author{
LIN Hong \\ Ningbo Dahongying University, Ningbo, China
}

\begin{abstract}
Language transfer is an important factor in second language acquisition, which consists of positive transfer and negative transfer. Positive transfer promotes the learning of the foreign language, while negative transfer interferes with language study. Language learners, no matter what level they are in, can hardly learn a language under the influence of native language, especially the negative influence of it. Because of it, errors seem to be an unavoidable phenomenon in the process of learning a foreign language. This paper takes non-English major students of Ningbo Dahongying University as research subjects. From the analysis of different errors in college English writing, the author can be certain of one point that the negative influence of MT (mother tongue) on word learning is reflected on multiple aspects.
\end{abstract}

Keywords: negative transfer of mother tongue, error analysis, contrastive analysis, English argumentative writing

\section{Introduction}

One cannot neglect the fact that language learners, no matter what level they are in, can hardly learn a foreign language well under the influence of MT (mother tongue), especially the negative influence of MT. Due to it, errors seem to be unavoidable phenomena in the process of learning a foreign language. When the college students write English compositions, the negative impact of MT is also very apparent. This paper aims at studying how and why the negative transfer of MTs affects college students' English writing. Negative transfer of MT with special reference of linguistic error in college students' writing is the subject of this paper. The paper aims at revealing interference of L1 (first language) in college students’ English writings, causes, and implication behind it.

Although the notion about language transfer has gone through several periods, MT transfer is inevitable the focus in second language writing, especially in the early stage of foreign language learning. From past to present, most people consider MT transfer as interference in the second language learning process. For linguists like Lado (1957) and Corder (1993), transfer was considered responsible for error occurrences in cross-linguistic and cross-cultural studies. Richards' (2001) contribution was that he evidenced that transfer of strategies was but partially responsible for the learner's errors. Transfer was studied and mentioned more and more indirectly as an apparent and essential factor of error. The research of MT was frequently contrasted with the basic features and hints of transfer. The theoretical categorization of the errors has also been researched and discussed in detail in recent decades.

LIN Hong, lecturer, Faculty of Humanities, Ningbo Dahongying University. 


\section{Methodology}

As we have discussed above, the precondition of the research is the hypothesis that native language does influence the students' EFL (English as a foreign language) writing. Generally speaking, the paper shows that how and to what extent negative transfer becomes an effect on students' writing. And in order to answer the question, the research is designed in detail to more specific research questions as the following: (1) What kinds of errors with MT interference occur in English samples of writing?; (2) What are the possible reasons of these errors in English samples of writing?; and (3) How to avoid these errors according to the implications of error analysis during writing?.

One hundred and seventy-eight subjects in three levels have been selected among Ningbo Dahongying University in major of Computer Science, Financial Administration, and International Trade. The number of students is 59, 59, and 60 respectively. For all of the students, they have at least learned English for more than six years. All the students are new sophomores, and have received two semesters college English teaching and have the experience of taking the CET-4 (College English Test-4) examination but not pass the exam. They were selected as the subjects also because they were different in English proficiency, from low intermediate, intermediate to low advanced according to their English scores of previous CET-4 which ensure the validity and reliability of the present study in variety of language level. Those whose scores are below 350 belong to the low intermediate group. Those whose scores are between 351 and 400 belong to the intermediate group and those whose scores are between 401 and 424 belong to the low advanced group. Students of the three groups have mastered a certain amount of vocabulary, some basic skills and strategies in EFL writing, such as how to organize a composition, how to write topic sentences, or how to start and end a composition, etc.. Therefore, they can represent the common level of non-English major students, and their writing can ensure the objectiveness of the study and be considered as samples.

The reason why the written form was chosen was that among the five basic skills in English learning, i.e., listening, speaking, reading, writing, and translating, writing is a productive skill, which can fully illustrate the MT's interference on learner's language competence. In addition, writing is a productive process, in which the lexical form is deeply involved and this is the necessary step for lexical analysis. All the subjects were asked to write a composition in the classroom. To ensure the reliability of the result of the experiment, they were not told that their writings were to be studied. All the students are required the same topic "what is happiness" to do writing. All the subjects are assigned to put down their opinions about the topic around 120 words. Thirty minutes of limited-time period are given to these students for the composition.

In doing the error analysis, the author follows the steps stated by Corder. First step is the collection of error samples. Second step is the identification or the classification of errors. The third step is the description of errors. And the fourth step is the explanation or analysis of these errors.

\section{Research Analysis}

According to Wardhaugh (2000), errors occur on three major levels of language. They are substance level, text level, and discourse level. Each level allows further classification, in terms of the following five categories: omission, redundancy, miss selection, disordering, and blends. Substance refers to phonological and graph logical systems. Text deals with lexical-grammatical systems. Discourse involves formulation or 
processing on the discourse level. The term text is sometimes used to refer exclusively to a unit of written language larger than the sentence for which paragraph might be a suitable term. James (2001) used text in a much broader sense to designate any instance of language that resulted from any ignorance and misapplication of the lexica-grammatical rules of the language. Text errors occur in three categories: lexis, morphology, and syntax.

Lexical errors can be classified into formal ones and semantic ones, each of which can be further subcategorized. Formal errors of lexis contain formal miss election, misformation, and distortion. Misselection refers to the wrong employment of pairs of words that look and sound similar. Misformations are errors that produce words non-existent in the TL (target language) and there are two types: borrowing which involves the use of MT word, coinage which refers to the use of the derived MT word which is the result of literal translation of a MT word. Distortions are forms non-existent in the TL. Semantic errors refer to learners' use of forms that exist in the TL but these forms do not represent the meaning they wish to express, confusion of sense relations and collocation.

Grammar errors can be classified into morphology ones and syntax ones, the former handling word structures, while the latter handling structures larger than the word. And in this paper, the analysis of grammar errors is about word structures instead of others. James (2001) pointed out that there are five lexical word types in English: noun, verb, adjective, adverb, and preposition. But in the paper, the classification of word errors covers all the parts of speech of English words.

All the linguistic errors in the samples collected were carefully found out. Since the aim of the research is to study MT interference on lexical employment, the category of lexical errors was further divided into subcategories according to different part of speech. For example, lexical errors include wrong choice of words, wrong collocations, and Chinese English. Meanwhile, the false use of grammatical rules was also analyzed among the process. The following types within intralingual errors will be involved in this paper (see Table 1).

Table 1

Types of Intralingual Errors

\begin{tabular}{|l|l|l|}
\hline Error type & \multicolumn{2}{|c|}{ Subdivision } \\
\hline Substance errors & Punctuation & Capital letters \\
\hline \multirow{4}{*}{ Lexical errors } & Noun & Preposition \\
\cline { 2 - 3 } & Verb & Pronoun \\
\cline { 2 - 3 } & Adjective & Article \\
\cline { 2 - 3 } & Adverb & Conjunction \\
\hline Grammar errors & Case & Number \\
\hline & Tense & Aspect \\
\hline Cohesion & Agreement & Word order \\
\hline
\end{tabular}

Despite the students' intermediate level of English proficiency, they still make many errors that could reflect the possible degree of Chinese interference on English learning. Some errors, though classified into intralingual errors, may be caused by other factors. However, in this paper, as long as Ll affects students' linguistic knowledge, the author will regard the errors as intralingual errors no matter how minor they play a subordinate role in the process of L2 production. 
According to James (2001), the type of errors in writing can be generally divided into interlingual errors and intralingual errors. Interlingual errors, in this paper were caused by negative transfer of MT, and intralingual errors were caused by improper application of grammatical rules in writing. The total number and the frequency were calculated in Table 2.

Table 2

General Classification of Errors in Writing Samples

\begin{tabular}{llrlrlr}
\hline General error type & \multicolumn{2}{c}{ Group one } & \multicolumn{2}{c}{ Group two } & \multicolumn{2}{c}{ Group three } \\
\hline Intralingual errors & 299 & $33.5 \%$ & 393 & $54.3 \%$ & 460 & $42.2 \%$ \\
Interlingual errors & 122 & $21.3 \%$ & 243 & $22.3 \%$ & 209 & $26.4 \%$ \\
Total errors & 421 & $54.8 \%$ & 636 & $76.6 \%$ & 669 & $68.6 \%$ \\
\hline
\end{tabular}

In the paper, the classification of errors for researching mainly refers to intralingual errors. And from the findings, we find that among the three groups, there are great amounts of percentage in intralingual errors, which prove that the study of intralingual errors is rather significant in evaluating students' quality of writing.

The following classification of the errors (see Table 3) is based on James' criteria of categorizing errors, that is, on the levels of language.

Table 3

Total Number and Proportion of Each Kind of Errors of Intralingual Errors

\begin{tabular}{llllll}
\hline & Substance & Lexicon & Grammar & Cohesion & Chinglish \\
\hline Number of errors & 158 & 592 & 554 & 234 & 188 \\
Percentage & $9.2 \%$ & $34.3 \%$ & $30.1 \%$ & $13.6 \%$ & $12.8 \%$ \\
\hline
\end{tabular}

According to James (2001), there are four levels of language: the level of substance, the level of lexicon, the level of grammar, and the level of cohesion and coherence. In addition to the above four levels of errors, another level is added in this study, the level of "idiomatic English" which is named "Chinese English". This type of classification according to linguistic items aims at giving a general description of the errors as the whole.

The actual number of the errors collected from the sample compositions is presented in Table 3 . The result shows that a total of 1,726 errors were collected out of all the writings. Of all these errors, lexical errors are the most distinctive, which count 592, about 34.3\% of the total; next comes 554 grammatical errors, accounting for $30.1 \%$ of the total. The numbers of the errors on the level of substance, cohesion, and Chinglish are 158, 234, and 188, accounting for 9.2\%, 13.6\%, and $12.8 \%$ respectively. Besides, it can also find that there is no obvious statistical difference between grammatical errors and lexical errors. They all account for about $30 \%$ of the total, with a discrepancy of $4.2 \%$. Substance errors are the least. So the focus of analysis later will primary on these two categories.

From Table 4, it can conclude clearly that what the exact correlation is among the five independent variables in detail. The result shows that a close relationship exists among the five categories of errors more or less When $p<0.05$, it means that there is positive correlation among them grammar and vocabulary, cohesion, and grammar. Surprisingly, when $p<0.01$, a significant correlation is found between Chinese English expressions and all the other four categories of errors. It is especially worthwhile noticing that cohesive errors have the highest correlation with Chinese English expressions ( $r=0.523$ ); the values of $r$ between grammar and 
Chinglish, substance and Chinglish are 0.413 and 0.4 respectively. Lexical errors also correlate with Chinese English expressions, but the value of $r$ is the lowest, which is 0.382 .

Table 4

The Analysis of Language Errors

\begin{tabular}{|c|c|c|c|c|c|}
\hline & Substance & Lexicon & Grammar & Cohesion & Chinglish \\
\hline Substance & & $0364 * *$ & $0.163 *$ & $0.352 *$ & $0400 * *$ \\
\hline Pearson correlation & & 0.003 & 0.324 & 0.021 & 0.002 \\
\hline Sig. (2-tailed) & & & & & \\
\hline Lexicon & $0.331 * *$ & & $0.329 *$ & $0.362 * *$ & $0.382 * *$ \\
\hline $\begin{array}{l}\text { Pearson correlation } \\
\text { Sig. (2-tailed) }\end{array}$ & 0.02 & & 0.47 & 0.03 & 0.001 \\
\hline Grammar & 0148 & $0236 *$ & & $0266 *$ & 0 \\
\hline Pearson correlation & 0.148 & $0 . \angle 3 b^{*}$ & & $0.266^{*}$ & $0.413^{*-2}$ \\
\hline Sig. (2-tailed) & 0.261 & 0.045 & & 0.034 & 0.000 \\
\hline Cohesion & $0.302 *$ & $0.364 * *$ & $0.284 *$ & & $0.523 * *$ \\
\hline $\begin{array}{l}\text { Pearson correlation } \\
\text { Sig. (2-tailed) }\end{array}$ & 0.003 & 0.002 & 0.031 & & 0.001 \\
\hline Chinglish & $0.412 * *$ & $0.389 * *$ & $0.425 * *$ & $0.336 * *$ & \\
\hline Pearson correlation & 0.001 & 0.002 & 0.000 & 0.000 & \\
\hline Sig. (2-tailed) & & & & & \\
\hline
\end{tabular}

Notes. * sample standard deviation; ** sample standard error.

In Table 5, we have got the exact percentage of these errors according to different linguistic items. And we can find that group three is the least in terms of the number as well as percent of the result. The sample analysis of errors will be taken out of this group. Among different parts of speech, errors on verb could be the most serious one, because they are so different with Chinese verb system. In the following part, the paper will analyze these errors in detail according to these linguistic items.

Table 5

Descriptions of Lexical Errors in Detail

\begin{tabular}{|c|c|c|c|c|c|c|c|}
\hline \multirow{2}{*}{\multicolumn{2}{|c|}{ Lexical error type }} & \multicolumn{2}{|c|}{ Group one } & \multicolumn{2}{|c|}{ Group two } & \multicolumn{2}{|c|}{ Group three } \\
\hline & & Number & Percent (\%) & Number & Percent (\%) & Number & Percent (\%) \\
\hline \multicolumn{2}{|c|}{ Article } & 9 & 4.4 & 18 & 6.1 & 23 & 6.3 \\
\hline \multicolumn{2}{|c|}{ Preposition } & 18 & 8.7 & 22 & 7.4 & 28 & 7.6 \\
\hline \multicolumn{2}{|c|}{ Pronoun } & 16 & 7.9 & 19 & 6.4 & 22 & 6.1 \\
\hline \multirow[t]{2}{*}{ Noun } & Countability & 15 & 7.4 & 20 & 6.8 & 31 & 8.5 \\
\hline & Misformation & 31 & 15.3 & 43 & 14.5 & 44 & 12.1 \\
\hline \multirow[t]{2}{*}{ Verb } & Transitivity & 27 & 13.3 & 32 & 10.8 & 40 & 11.0 \\
\hline & Verb pattern & 30 & 14.8 & 51 & 17.2 & 59 & 16.2 \\
\hline \multicolumn{2}{|c|}{ Semantic collocation } & 10 & 4.9 & 24 & 8.1 & 18 & 4.9 \\
\hline \multicolumn{2}{|c|}{ Choice of word } & 13 & 6.4 & 26 & 8.8 & 37 & 10.2 \\
\hline \multicolumn{2}{|c|}{ Conjunction } & 34 & 16.9 & 40 & 13.9 & 62 & 17.0 \\
\hline \multicolumn{2}{|l|}{ Total } & 203 & 100.0 & 296 & 100.0 & 364 & 100.0 \\
\hline
\end{tabular}

Table 3 clearly indicates that lexical errors are most noticeable, which account for $34.3 \%$ of the total, which has just coincided with most findings on the errors of EFL learner's writings. Many researchers have found that lexis has more direct effect on writing compared with the other levels of language.

The reason why English lexical system is so difficult to acquire is the negative transfer on though 
patterns. As has been mentioned before, English is a structurally compact language, while Chinese is a logically compact language. First, different thought patterns result in the difference in using cohesive ties of the two languages. The high correlation among cohesive ties shows that the students are ignorant of different thought patterns of the two languages.

Table 5 shows that the total number of errors on conjunction is 136, higher than most of the other item. The average of percentage is $15.9 \%$. This tells us how the Chinese students lack of the awareness to employ English cohesive device. Once again, the questionnaire and interview designed in the study shows that the students especially the less advanced students' incapability of taking cohesive device into consideration. From the organization to concrete expression, most students rely on their Chinese thought patterns to solve all the problems they might meet.

On lexical level, students hardly employ other strategies to get rid of the problem of vocabulary and mind blank. When dealing with a concept, the Chinese equivalence occurs first in their mind. And if they cannot find the proper one, they will most probably use the coinage of words or phrases according to the Chinese expression, which are in most cases non-existent in English. Among these samples, there exists a great amount of Chinese English, which indicates that these learners are involved deeply with MT interference in terms of thought patterns. It seems that great importance should be attached to helping the students to develop English thought patterns to deal with concept as well as structure, so that the negative influence of their MT could be reduced to the most extent.

How to form English thought pattern is an urgent but tough job for Chinese learners. As kind of deposition of MT, Chinese thought pattern has been deeply rooted in learners' mind. The finding of "stereotypical-relation model" is considered to be a good way of helping the Chinese EFL learners to form English thought pattern. The explanation of stereotypical relation is the relation among referents of events. The model is that "if A occurs, B will occur, then A and B are in the same stereotype" (Cook \& Seidlhofer, 1999, p. 67). One point is that the stereotypical relation is culture-based and thus we may conclude that different culture has different stereotypical relation.

The consciousness of this difference is essential for learners. What is more, learners needs to work out the fact about how to convert this consciousness to the ability to learn words and give correct output. The requirement is that as student learners, we should deal with native language material as much as possible so that we can be involved in cultural atmosphere. It is a great help in writing. The understanding of the culture-oriented stereotypical relation is the key to forming English thinking pattern. Therefore, teachers should consciously introduce it to the students in their teaching of writing. There are some suggestions on how to help students form English stereotype-relation. Some are especially practicable and effective in classroom. One is by annotation; the other is by classroom activities.

MT is the L1 system established when the learner has not established any other language systems yet. Foreign language is the second language system when the MT system has been well established. MT is generally developed in MT environment. Every nation has its own culture and has particularity. Native people naturally absorb their own culture in the process of growth and education, usually without detailed explanation. In long term, people focus on inner cultural system, totally separating language and culture. The result is that foreign language teaching emphasizes linguistic forms, particularly written language study and sets mastering 
grammar knowledge and practicing sentence pattern as main contents for study, seriously detached from cultural context and ignoring cultural features of the target culture, applying MT cultural habit and cultural mode to the learnt language, and thus cause cultural interference. Negative transfer of MT culture mainly manifests in the following three aspects.

Cultural connotation of vocabulary generally refers to its emotion embodiment, style and figurative meaning, etc.. As different cultural background may lead to different social concepts, there may be different cognitions towards the same matter. Without comparison and attention, and just applying with the MT cultural mode, misunderstanding may occur. For example, Chinese students are accustomed to translating Chinese idiom “健壮 如牛” in their English writing like “as strong as a cow”, actually, the authentic English expression should be “as strong as a horse". Some matters or phenomena may exist in both cultures or are similar. However, different cultural backgrounds may bring people with different associations and unique emotional comment. What is more, there are many words that have similar literal meaning but greatly different actual meanings. So we can see in vocabulary, the main manifestation of negative transfer of MT culture on English study is: Concept of the words in English is not equivalent to that of the learner's mother language, or the words have emotion embodiment unique for some nation. This requires us not to teach vocabulary separately. Instead, we should put it in some cultural background, pay attention to comparison between two different cultural backgrounds, and start from the words' cultural connotation to let students understand difference between English and Chinese words and their different expression forms in language.

Linguistic communicative function is common, but cultural difference has caused significant differences in language use among different language social groups, and also has brought great difficulties for communication among different cultures. In daily life, behaviors like greeting, salutation, acknowledgement, wish, apology, courtliness, euphemism, taboo, etc., all somehow carry fixed modes limited by culture. For example, “谢谢” in Chinese is often used while we accept others' help or service, but if we apply this concept into English conversations, misunderstanding may happen. Suppose an Englishman asked his Chinese friend: “Would you like a cup of tea?” If Chinese answered: “Thanks”, Englishman was puzzled and he did not know whether he should offer the coffee or not. So in this situation, if the Chinese wanted to have a cup a coffee, he needed to say: "Yes, please”. If he did not, he should reply: "No, thanks". Different expressions are used according the language cultural custom.

\section{Implications}

Until now, the analysis of the writing errors and its reasons in this study revealed that the problem of MT transfer in students' vocabulary in writing is a complicated phenomenon. The main problem of the students' errors is not the small vocabulary size, but the improper use of the words or wrong collocation of words in composition. According to the College English Syllabus (2001) for non-English Majors, students need to master more than several thousand English words when they have finished English learning in college. But the number itself is not equal to the writing ability, because the latter is kind of collocation of words in sentence level. The notion that knowing so many words is quite enough for them to express their ideas is worth to be revalued. It seems that the problem for Chinese EFL learners does not lie in whether they can write down a considerable 
number of words in English, but whether they can communicate in an efficient, appropriate, and natural way. Based on the causes of high frequency of lexical errors, teachers should on one hand attach great importance to lexical teaching in class, on the other hand help the students to get rid of the false assumption on the semantic and syntactic equivalence of English and Chinese words.

To be exact, the quality of language input should be improved in English writing teaching. The process is carried out mainly within class and the quality of this input has great impact in the effect of English learning. When teaching vocabulary, several points should be noticed. First, it is about the stylistic feature of the vocabulary, and the word of speech is also very important for a new word, because it determines the usage of this word. Second point is about the association between signal word and the situation it appears, and this can be done by employing situational and communicative approach so that students know how to use the word in real situation. Third, teachers should pay attention to the difference between Chinese and English and try to help students realize the Chinese and English lexical difference. For example, when illustrating a new word, teachers should come up with some effective teaching methods, and use English to explain English so that the tie of negative transfer cannot be built. Fourth, teachers ought to connect new words to old ones, so that free association can be realized.

Through analyzing the specific example of sentence with language error, students get more intensive understanding of how words are tend to be misused in practice. This is also a good way to improve sentence writing quality in terms of English learning. On the one hand, the reason of negative transfer is illustrated by examples, and on the other hand, deep understanding of certain kind is intensified through close reading and analyzing. In addition, learning good passages by heart is an effective way of learning usage of words as well as language background and culture. The sensitivity to language is increased by reciting and potential language structure will be expanse during the process. According to the survey and statistics, students who recited more words, phrases and passages score higher in English writing. The frequency of errors will be lower. Thus, purposeful reciting, especially for elementary language learners, can partly solve the problem of MT negative transfer in English writing.

\section{Conclusions}

The paper has answered the following questions through experiment and analysis. First, different standards of classification are employed in the research in order to get the data on percentage of linguistic errors as a whole. Second, the research indicates that errors in college English writings are primary and urgent problem. Third, the paper makes future discussion on errors according to different part of speech and gives explanation from the view of negative transfer. By exploring the reasons of interlingual and intralingual errors, the paper shows how negative transfer has functioned in English writing. Based on the assumption, implications of the present study are also discussed. Based on the theory of contrastive analysis and error analysis, the writing errors are divided into four groups that are substance, lexicon, grammar and cohesion. The study of the learners' errors shows the interference of MT in students writing. By application of Excel and SPSS (Statistical Product and Service Solutions), the frequently occurring writing errors were picked out. These errors also distinguish the low advanced, the intermediate, and the low intermediate groups of students. The paper indicates that errors in writing are of positive meaning. They provide feedback; they tell the teachers something about the effectiveness of his 
teaching materials and his teaching techniques. The study of transfer errors also provides researchers with a picture of the language development of the learners and may give us indications or evidences of how a new language is learnt or acquired. Some influential factors are emphasized such as the complexity of English system, the different restrictions of syntax rules, and the significance of thought pattern. Although the paper is informative and reflective for teachers as well as learners, it is still confined by conditions and needed to be further studied. For instance, the writing samples are collected only in the author's university and only the sophomore students take part in the study. Therefore, the findings cannot be generalized to all the universities at least in one city. In the future, further research will be conducted to find out more effective solutions to reduce negative transfer in college students' writing.

\section{References}

Benson, C. (2002). Transfer and linguistic influences. ELT Journal, (56), 68-70.

Charles, C. F., \& Lado, R. (2003). Knowledge of language: Its nature, origin and use (p. 202). New York: Praeger.

Chomsky, N. (1986). Knowledge of language (pp. 110-113). New York: Praeger.

Cook, G., \& Seidlhofer, B. (1999). Principles and practice in applied linguistics (p. 67). Shanghai: Shanghai Foreign Language Education Press.

Dulay, H. C., Burt, M. K., \& Krashen, S. D. (1982). Language two (pp. 113-115). New York: Oxford University Press.

Harris, Z. S. (1951). Methods in structural linguistics (pp. 77-78). Chicago: Chicago University Press.

Howatt. A. (2004). A history of English language teaching (pp. 64-66). Oxford: Oxford University Press.

James, C. (2001). Errors in language learning and use: Exploring error analysis (pp. 69-70). Beijing: Foreign Language Teaching and Research Press.

Lennon, P. (1991). Error: Some problems of definition, identification, and distinction. Applied Linguistics, $12(2), 66$.

Odlin, T. (1989). Language transfer: Cross-linguistic influence in language learning (p. 89). Shanghai: Shanghai Foreign Language Education Press.

Richards, J. (2001). Error analysis, interlanguage, and second language acquisition: A review. In the Context of Language Teaching (p. 107). Beijing: Foreign Language Teaching and Research Press.

Wardhaugh, R. (2000). The contrastive analysis hypothesis. TESOL Quarterly, 2(2), 98-100.

Widdowson, A. C. (1997). Language proficiency, writing ability, and composing strategies: A study of ESL college student writers (p. 116). New York: St. Martin’s Press.

Wilkins, D. A. (1972). Linguistics in language teaching (pp. 35-37). Oxford: Edward Arnold. 